Leader to Leader, (2010) Winter: 45-51.

\title{
Five Keys to Flourishing in Trying Times
}

\author{
Kim Cameron \\ University of Michigan
}

We are in the midst of the most severe recession in the memory of anyone alive. Many experts estimate that the causes of this recession are more severe than those that created the Great Depression in the late 1920s. No country in the world has escaped a major downturn in its economic viability, and organizations around the globe are predicted my most economists to face on-going fiscal stress for years to come. Because the downturn is unprecedented, few clear guidelines exist for leaders regarding how to effectively respond to the unparalleled challenges.

In this article I rely on two decades of empirical research on organizations that have faced difficult economic situations but which have achieved levels of success that are unexpected and exceptional. Carefully examining these organizations has helped uncover some atypical leadership strategies that can serve as guidelines to leaders facing tying times. These strategies are atypical in that they supplement the oftprescribed leadership truisms that appear in the popular press, and they are less often recognized by leaders facing trying times.

These strategies are based on the concept of positive, and they have emerged from the newly developing field of Positive Organizational Scholarship. This field of study focuses on positively deviant organizational performance, or successful performance that dramatically exceeds the norm in a positive direction. It investigates affirmative dynamics, or an orientation toward strengths rather than weaknesses and abundance rather than deficits in organizations. It examines virtuousness and eudaemonism, or on the best of the human condition and that which people consider to be inherently good.

It is not unusual for positively-biased areas of scientific investigation to be dismissed as saccharine, naive, or irrelevant in the face of threatening economic conditions. In fact, positive terms such as virtue, caring, compassion, and goodness have appeared rarely in the business press in the last 20 years, whereas negatively biased words such as beat, fight, win, and compete have increased fourfold in the same period. Business leaders give more attention to the negative than to the positive, especially in trying times.

One key finding from my research is that a focus on the positive produces the heliotropic effect. This effect is defined as the tendency in all living systems toward that which gives life and away from that which depletes life-toward positive energy and away from negative energy. Because all living systems have an inclination toward the positive-for example, plants lean toward the light, people remember and learn positive information faster and more accurately than negative information, positive words predominate over negative words in all languages, human brains are activated more by 
positivity than by negativity-leaders that capitalize on the positive similarly tend to produce life-giving, flourishing outcomes in organizations. A focus on the positive is lifegiving for individuals and organizations in the same way that positive energy in nature enhances thriving in living organisms. This is especially so in circumstances that seem threatening, stressful, and worrisome.

Crises, threats, inadequate resources, deterioration, and stress characterize trying times. The most frequent reaction to such conditions is hunkering down, protectionism, problem orientation, and defending against anxiety. Common human experience, as well as abundant scientific evidence, supports the idea that emphasizing the negative is necessary and adaptive in such circumstances. Negative news sells more than positive news, people react to negative feedback more than positive feedback, and traumatic events usually have greater impact on humans than positive events, and for good reason.

Moreover, it is clear from research that human beings respond more strongly to negative phenomena than to positive phenomena. They learn early in life to be vigilant in responding to negative events and stimuli because such factors could be dangerous or harmful. Thus, in trying times, reacting to and protecting against negativity tends to predominate in leaders' actions. Two decades of my own research have confirmed, however, that successful positive responses are not dependent on completely positive conditions, just like languishing and failure are not dependent on completely negative conditions. Positive strategies are highly effective in threatening as well as in benevolent situations.

My own studies of organizations that have downsized, faced bankruptcy, experienced loss of mission, and encountered fiscal disasters have produced at least five keys to flourishing in trying times. These keys all have emerged from investigations of organizations that achieved unexpected and extraordinary success when facing difficult economic circumstances. Each key is enumerated below along with a brief explanation of some of the studies that produced the recommendations for how to help organizations flourish in trying times.

Key \#1: Capitalize on the heliotropic effect.

Because all human beings have an inherent inclination toward positive energy and toward that which is life-giving, leaders who capitalize on this heliotropic tendency can produce flourishing, even in trying circumstances. For example, a study of the cleanup and closure of a nuclear weapons production facility near Denver, Colorado, illustrates the power of leading positively even in the face of overwhelming obstacles.

In the 1990s the facility was rife with conflict and antagonism. The site had been raided and temporarily closed by the Federal Bureau of Investigation in 1989 for alleged violations of environmental laws, and employee grievances had skyrocketed. More than 100 tons of radioactive plutonium was on site, and more than 250,000 cubic meters of low-level radioactive waste was being stored in temporary drums on the prairie. Broad public sentiment existed that the facility was a danger to surrounding communities, and demonstrations by multiple groups had been staged from the 1960s through the 1990s in protest of nuclear proliferation. Radioactive pollution levels were deemed to be so high that a 1994 ABC Nightline broadcast labeled it the most dangerous buildings in 
America. The Department of Energy estimated that to close and clean up the facility would require a minimum of 70 years and cost more than $\$ 36$ billion.

The engineering and environmental firm that won the contract to clean up and close the 6,000-acre site, consisting of 800 buildings, completed the assignment 60 years ahead of schedule, $\$ 30$ billion under budget, and 13 times cleaner than required by federal standards. Antagonists such as citizen-action groups, community mayors, and state regulators changed from being adversaries and protestors to advocates, lobbyists, and partners. Labor relations among the three unions (i.e., steelworkers, security guards, building trades) improved from 900 grievances to the best in the steelworker president's work life. A culture of lifelong employment and employee entitlement was replaced by a workforce that enthusiastically worked itself out of a job as quickly as possible. Safety performance exceeded federal standards by twofold and more than 200 technological innovations were produced in the service of faster and safer performance. These achievements far exceeded every knowledgeable expert's predictions of performance.

Two excerpts from interviews with employees at Rocky Flats illustrate their emphasis on positive leadership.

From an executive at the Department of Energy: "The leadership from the organization was very important. ... They poured their corporate heart into what we were trying to do. They brought some fabulous positive leadership to the site."

From the CEO of the firm: "The biggest difference I see between now and 1995 is that, if we went into a building or went around the site . . the employees weren't proud of what they were doing. They didn't care. There was negativity all around. You go into the buildings now and it's a totally different feeling. The energy that people put into their work is obvious. The involvement, the pride, the humor, the positivity-you wouldn't even know this was the same place it was in 1995."

Virtually all human beings desire a positive work environment, and in trying times capitalizing on the heliotropic effect is especially crucial.

Key \#2: Manage economic downturns virtuously.

A study of the U.S. airline industry revealed that, after the tragedy of September $11^{\text {th }}$, the number of passengers flying on U.S. airlines topped out at 80 percent of pre2001 ridership levels. Because the economic model of the airline industry was based on $86 \%$ seat-fill rate, all of these companies were losing money. They were all faced with at least $20 \%$ too many pilots, gate agents, mechanics, and so forth. The companies dependent on short-haul routes were especially hard hit because many people chose to drive or take a train rather than fly to locations that were only a few hours away.

As expected, the decision to downsize was almost universal in the industry, but companies approached the task in very different ways. One company that emphasized short-haul routes, for example, declared financial exigency and eliminated almost $25 \%$ of its employees with no severance benefits.

Southwest Airlines, also a short-haul carrier, chose to eliminate no jobs. Despite losing several million dollars per week in the weeks following the attacks, Southwest refused to lay off employees. This decision was explained by former CEO Jim Parker: 
"Clearly we can't continue to do this indefinitely, but we are willing to suffer some damage, even to our stock price, to protect the jobs of our people." The rationale was explained as follows: "You want to show your people that you value them, and you're not going to hurt them just to get a little more money in the short term. Not furloughing people breeds loyalty. It breeds a sense of security. It breeds a sense of trust."

Southwest had built up healthy financial reserves for just such a contingency, and the firm had resisted Wall Street pressure to take on more debt in order to be able to respond virtuously in just such a crisis.

It is unrealistic, of course, to assume that companies can avoid downsizing in the current economic downturn. My own research on downsizing over the last 20 years has found, however, that the way downsizing occurs is more important than the fact that it occurs. In a study of a large number of downsizing firms in 16 different industries, strong and statistically significant relationships were found between virtuous practicescharacterized by high levels of compassion, forgiveness, gratitude, integrity, optimism, trust, and so on-and both objective outcomes such as profitability, productivity and quality and subjective outcomes such as morale, customer loyalty, and employee engagement. Organizations that implemented virtuous practices performed significantly better than those that did not.

\section{Key \#3: Focus on abundance gaps.}

Abundance gaps represent the difference between normal, acceptable performance and extraordinary or "positively deviant" performance. Think, for example, of a line representing a continuum. The left side of the continuum represents ineffective, inefficient, error-prone performance. This could be a state of illness or problem-ridden conditions and might be termed negatively deviant. The middle point on the continuum represents normal or expected performance, characterized by effectiveness, efficiency, and reliability. This is the most common and healthy state of individuals and organizations. The right side of the continuum represents positive deviance, or exceptional, outstanding, and even virtuous performance. The best of the human condition is characterized by this end of the continuum.

The gap between the left side of the continuum and the middle is referred to as a deficit gap. The gap between the middle point and the right side of the continuum is referred to as an abundance gap. In trying times, deficit gaps tend to dominate leaders' attention. Problem solving overshadows almost all other activities. Obstacles and difficulties cannot be ignored, of course, but they tend to drive out a focus on abundance gaps. My own research has found, for example, that leaders who focus at least as much on abundance gaps as on deficit gaps produce far higher levels of performance.

For example, in a study of the effectiveness of 30 units in a large health care system, the units that emphasized abundance gaps and implemented positive practices-compared to normal units that focused mainly on solving problems, treating illness, and closing deficit gaps-achieved substantially higher levels of performance over a three year period of time regarding employee satisfaction, patient satisfaction, quality of care, engagement of employees, relationships with other professionals, and employee turnover. A conscious focus on abundance gaps produced improvement in 
both problem solving (responding to negative deviance) and flourishing (fostering positive deviance).

Similarly, a study 60 top management teams conducted by Marcial Losada also confirmed this finding. These teams were formally observed working on their own organizational issues for one day, and their communication patterns were coded into several categories. One category was the number of positive statements made relative to the number of negative statements made during the day. A positive statement is helpful, caring, approving, congratulatory, and so on. A negative statement is derogatory, critical, disapproving, contradictory, and so on. The performance of these top teams' companies were also assessed based on profitability, productivity, and leadership competence. High performing companies used 5 positive statements for every negative statement during the day. Low performing companies used 3 negative statements for every positive statement. That is, when the communication of senior executives was biased toward the positive, or toward abundance gaps, performance was substantially affected. While not ignoring problems, leaders that emphasized abundance gaps produced flourishing.

Key \#4: Create positive energy in the face of decline.

Recent research has found that individuals can be identified as "positive energizers" or "negative energizers," and the difference has important implications in trying times. Positive energizers create and support vitality in others. They uplift and boost people. Interacting with positive energizers leaves others feeling lively, inspired, and motivated. In contrast, negative energizers deplete the good feelings and enthusiasm of others. They sap strength from and weaken people. They leave others feeling exhausted and diminished

Positive energizing is a learned behavior, not a personality attribute. The correlation between being a positive energizer and being an extravert, for example, is essentially zero. Being a positive energizer is not a matter of being gregarious or outgoing. People learn how to become positive energizers, and it is a developed competency rather than an inherent attribute.

Positive energizers benefit their organizations by enabling others around them to perform better. Research by Wayne Baker has shown, for example, that a person's position in an energy network is far more predictive of success than a person's position in an information network or an influence network. Specifically, being a positive energizer made individuals four times more likely to succeed than being at the center of an information network or by being the most influential person in the organization. Positive energizers also increased the level of energy of others with whom they worked, and the amount and richness of communication was significantly higher with positive energizers compared to neutral or de-energizing people. Interpersonal relationships, collaboration among colleagues, and the efficiency of work being done all were positively affected by individuals who exuded positive energy.

One of the best examples of positive energy in the midst of decline was the leadership displayed by Lee lacocca when he transformed the Chrysler Corporation in the 1980s. Research was conducted in which lacocca's speeches to his top management team during his tenure as CEO were carefully examined. This 
examination revealed almost non-stop positivity being communicated to the senior team by lacocca. This communication was authentic and honest-rather than cheerleading and marketing-hype-and it emphasized positive factors at least five times as much as negative factors. In a challenging environment that clearly matches the severity of the current economic climate, Chrysler went from bankruptcy to world-record profits in 5 years. Most executives in the firm attribute this transformation to lacocca's positive energy. Studies have confirmed that the highest performing organizations are not only led by positive energizers, but they have three times the number of positive energizers in the workforce as normal organizations.

Key \#5: Implement positive practices even in industries that don't seem to value them.

Many critics indicate that a focus on positivity by leaders may be appropriate in a limited number of circumstances, but this orientation is certainly not appropriate for most organizations in trying times. Wall Street financial firms, for example, are among the least likely places to consider positive strategies. An almost-exclusive focus on shortterm monetary returns, high-pressured environments, financial trading, and a win-at-allcosts climate is typically characteristic of this sector. Human concerns and virtuousness are not typically considered to be dominant attributes of hard-charging companies whose success would seem to depend on brutal competition more than human virtues.

Similarly, it is common knowledge that the United States is currently at war on at least two major fronts. The U.S. Army is usually considered to be charged with a mission to destroy things and to kill the enemy. The best soldiers and the best units are assumed to be those that can best carry out those missions. A command and control culture along with rigid hierarchies and an emphasis on strict obedience to military doctrine appear to be antithetical to a focus on abundance, virtuousness, and positivity.

It is important to point out, however, that research was conducted in both of these industry sectors, and the findings are consistent with those found in other kinds of organizations. In 40 financial services organizations, for example, the correlation between positive, virtuous practices and financial performance in these organizations was 0.49 . Firms that were more compassionate, forgiving, grateful, trustworthy, teachable, and so forth were significantly more profitable over a two year period than firms that were not. Moreover, firms that improved their positive practices over this period of time also significantly improved their financial results. Almost half the variance in financial outcomes in the successful financial organizations could be accounted for by changes in their positive practices.

Similarly, investigations of the U.S. Army over the last decade revealed parallel findings. Successful Army commands have adopted what they refer to an as a caring culture:

"The employees of the Army know that their Command is committed to doing whatever it has to do to take care of the people here. Most of our employees . . realize the Command is looking for the greater good. They are confident in the Command's commitment to them, that they will be taken care of. We stand by our word, and people see that. (A Senior Command Officer).

More significantly, a change in the orientation and culture of the Army can be seen by an increasing emphasis on positivity. The head of solider training for a major 
Army facility recently explained the current approach taken to soldier preparation and instruction:

"Our soldiers are the best fighters in the world, but we are teaching them how to avoid fighting all together. We have adopted an abundance culture. We will fight-and winif we have to, but we want to be a military that teaches the world that we do not need to fight to obtain the desired objectives." (U.S. Army General, 2009)

In sum, positive leadership focuses on what elevates individuals and organizations (in addition to what challenges them), what goes right in organizations (in addition to what goes wrong), what is life-giving (in addition to what is problematic or life-depleting), what is experienced as good (in addition to what is objectionable), what is extraordinary (in addition to what is merely effective), and what is inspiring (in addition to what is difficult or arduous). Positive leadership means promoting outcomes such as thriving at work, interpersonal flourishing, virtuous behaviors, positive emotions, and energizing networks. Especially in trying times, this kind of leadership is rare, but it is essential if organizations are to flourish. Capitalizing on the heliotropic effect, managing economic downturns virtuously, focusing on abundance gaps, creating positive energy in the face of decline, and implementing positive practices even in industries that don't seem to value them are all keys to flourishing in trying times.

Kim Cameron is William Russell Kelly Professor of Management and Organizations at the University of Michigan's Ross School of Business and is co-founder of the Center for Positive Organizational Scholarship. His current research focuses on virtuousness in and of organizations and their relationships to performance. He and several colleagues teach two week-long executive education programs sharing the practical tools and techniques that have emerged from their investigations of positive leadership and positive organizations. You can learn more about these programs and about positive leadership at http://execed.bus.umich.edu/Subjects/Leadership.aspx. 